\title{
Preparation and Anti-Corrosive Properties of Cerium Oxide Conversion Coatings on Steel X52
}

\author{
Mohammad Reza Majdi ${ }^{a}$, Iman Danaee ${ }^{a *}$, Seyyed Salman Seyyed Afghahi \\ ${ }^{a}$ Abadan Faculty of Petroleum Engineering, Petroleum University of Technology, Abadan, Iran \\ ${ }^{b}$ Department of Materials Science and Engineering, Imam Hossein University, Tehran, Iran
}

Received: Setember 12, 2016; Revised: November 25, 2016; Accepted: January 15, 2017.

In this study, cerium-based conversion coating was deposited on steel X52 by dip immersion method. Cerium oxide/hydroxide is an environmentally friendly conversion coating. The effects of immersion times and immersion temperatures on corrosion properties of cerium conversion coating on steel X52 were studied. Its corrosion resistance in $3.5 \mathrm{wt} . \% \mathrm{NaCl}$ solution was investigated by means of electrochemical impedance spectroscopy, potentiodynamic polarization, and surface techniques. The coated samples showed a significant decrease in corrosion rate and corrosion current decreased with increasing immersion time up to $60 \mathrm{~s}$. In addition, electrochemical impedance data showed that in the presence of cerium oxide conversion coatings, the charge transfer resistance of aluminum increased. The experimental results indicated that the corrosion resistance decreased with increasing the operating temperature. Surface morphology and its chemical composition were analyzed by means of scanning electron microscopy and energy dispersive spectroscopy.

Keywords: Steel X52; Cerium oxide coatings; Impedance; SEM

\section{Introduction}

Steel is the most frequently used metal in various industries due to its good mechanical properties. Despite relatively limited corrosion resistance, steel is used in large tonnages in marine applications, chemical processing, petroleum production and refining, construction and metal processing equipment $t^{1,2}$. The economic consequences of iron corrosion and its alloys in various industrial sectors, including oil and gas operations, are investigated ${ }^{3}$ and therefore much efforts have been carried out to enhance corrosion resistance of steel ${ }^{4,5}$.

There are different ways to control corrosion including inhibitors, coatings, applying anodic/cathodic protection and proper design $^{6-9}$. Surface treatment is an effective technique to solve the problem, which includes chemical conversion coating, electroplating and electroless plating, physical vapor deposition and so on ${ }^{10-12}$. Among these surface treatments, chemical conversion treatment is a simple and cost effective method and has been increasingly used in a wide range of applications. Conversion coatings are used in metal finishing to afford corrosion protection and to improve the adhesion of paint systems to the underlying metal ${ }^{13,14}$. The conversion coating acts as a physical barrier to protect the metal from corrosive environment. The protective value of such coatings depends on continuity and thickness of coating. The local cracking of the conversion coatings decreases the corrosion resistance.

* e-mail:danaee $@$ put.ac.ir
Chromate conversion coatings ( $\mathrm{CrCC}$ ) have been widely used for the surface treatment in industry to improve the corrosion protection of many metallic substrates such as steel, galvanized steel, aluminum and magnesium alloys ${ }^{15,16}$. However, hexavalent chromium presents very high toxicity and has unusual environmental impact ${ }^{17-19}$. For this reason, an intense research effort is being undertaken to replace chromates by more environmentally friendly compounds. Environmentally-friendly alternatives to $\mathrm{CrCC}$ have been investigated as potential replacements and include rare earth inhibitors and coatings, and sol-gel, among others ${ }^{20-22}$. It has been reported that (salts with) rare-earth ions such as $\mathrm{Ce}$, $\mathrm{La}, \mathrm{Pr}, \mathrm{Nd}$, and $\mathrm{Y}$ used as adhesion promoters and provided suitable resistance to corrosion through the formation of insoluble hydroxide/oxide layers ${ }^{23-28}$. Because of their low toxicity, rare-earth salts are not considered as health hazard materials. Consequently, coatings containing rare-earth elements have been recommended as potential replacements for chromate-based formulations in metal finishing ${ }^{29,30}$.

Cerium conversion coatings are one of the most promising environmentally friendly surface treatments for a range of metals ${ }^{31-33}$. Cerium conversion coatings have been investigated in many works for different aluminum alloys, magnesium alloys, tin, and zinc alloy ${ }^{34,35}$. But very limited experiments were done on steel alloys. Onofre-Bustamante et al. ${ }^{36}$ studied the role of $\mathrm{H}_{2} \mathrm{O}_{2}$ in the formation of cerium-based conversion coatings as an alternative to hexavalent chromium conversion coating for corrosion protection of commercial carbon steels. 
They showed that $\mathrm{H}_{2} \mathrm{O}_{2}$ favored the precipitation of cerium oxide/hydroxide on the metal surface and could help to obtain coatings with enhanced corrosion resistance and adhesion strength properties.

In this work, cerium conversion coating was deposited on steel X52 by chemical dip immersion method in different temperatures and immersion times. The surface morphology of cerium coated samples was assessed by scanning electron microscope (SEM) and the composition of the coating surface was evaluated by EDX analysis. Corrosion resistance of these coatings was investigated by polarization curve and electrochemical impedance spectroscopy (EIS) in 3.5\% sodium chloride solution. The dip immersion is a simple and inexpensive method in comparison with other methods.

\section{Materials and methods}

Cerium-based conversion coatings were deposited on steel X52. The specimens were cut to $1 \mathrm{~cm} \times 1 \mathrm{~cm}$ samples from larger panels. Prior to surface pretreatments process, all samples were mounted in epoxy resin. Then, steel coupons were mechanically abraded with abrasive papers (400-2000 mesh). The specimens were de-smutted by rinsing with acetone and then, panels were immersed in a $\mathrm{H}_{2} \mathrm{SO}_{4}$ solution. Between each step of the pretreatment process, the samples were rinsed with deionized water. Pretreated samples were coated by immersing in a cerium solution at a special temperature for particular time. The coating bath contained $0.6 \mathrm{~g} \mathrm{CeCl}_{3}$, three drops glycerin, and $2 \mathrm{ml} \mathrm{H}_{2} \mathrm{O}_{2}$ in $100 \mathrm{ml}$ deionized water. After coating preparation, they were stored at room temperature in the ambient laboratory air for $24 \mathrm{~h}$. This leads to drying of coating which increases corrosion resistance.

Corrosion behavior of cerium-based conversion coatings was evaluated by using electrochemical impedance spectroscopy and polarization curves. Potentiostat/galvanostat model PGSTAT 302N was used for electrochemical experiments. A three-electrode cell system containing $3.5 \mathrm{wt} \% \mathrm{NaCl}$ solutions was applied for corrosion tests. $\mathrm{Ag} / \mathrm{AgCl}$, platinum, and steel X52 working electrode were used as reference, counter, and working electrode, respectively. The potential was scanned at a rate of $1 \mathrm{mV} \mathrm{s}^{-1}$. Polarization parameters were calculated by the Tafel extrapolation method. A frequency sweep from $100 \mathrm{kHz}$ to $10 \mathrm{mHz}$ was used for EIS measurements with AC amplitude $10 \mathrm{mV}$ at open circuit potential (OCP). Fitting of experimental impedance spectroscopy data to the proposed equivalent circuit was done by means of a home written least square software based on the Marquardt method for the optimization of functions and Macdonald weighting for the real and imaginary parts of the impedance ${ }^{37,38}$. Scanning electron microscopy (SEM, VEGA, TESCAN-LMU) equipped with energy dispersive spectroscopy (EDX) was used to characterize the surface morphology and average chemical composition of coatings.

\section{Results and discussion}

\subsection{Effect of immersion time}

Polarization curves of cerium oxide coated steel X52 electrodes are shown in Figure 1. The electrochemical behavior of the cerium oxide coatings after different immersion times was studied by potentiodynamic polarization in $3.5 \mathrm{wt} \% \mathrm{NaCl}$ solution. The anodic and cathodic polarization branches in Figure 1 demonstrate Tafel type behavior of these samples. Table 1 exhibits the corrosion parameters such as corrosion potential (Ecorr), corrosion current density $\left(I_{\text {corr }}\right)$, polarization resistance $\left(R_{p}\right)^{39}$, and Tafel slopes $\left(\beta_{a^{\prime}} \beta_{c}\right)$. According to Table 1 , the corrosion current density and corrosion rate decrease in the presence of cerium oxide/hydroxide coatings. The decrease in corrosion rate indicates the barrier properties of the cerium oxide/hydroxide films on the steel substrate in a corrosive environment. The deposition mechanism involves both the oxidation of iron and the reduction of $\mathrm{H}_{2} \mathrm{O}_{2}$ in the reaction ${ }^{40,41}$ :

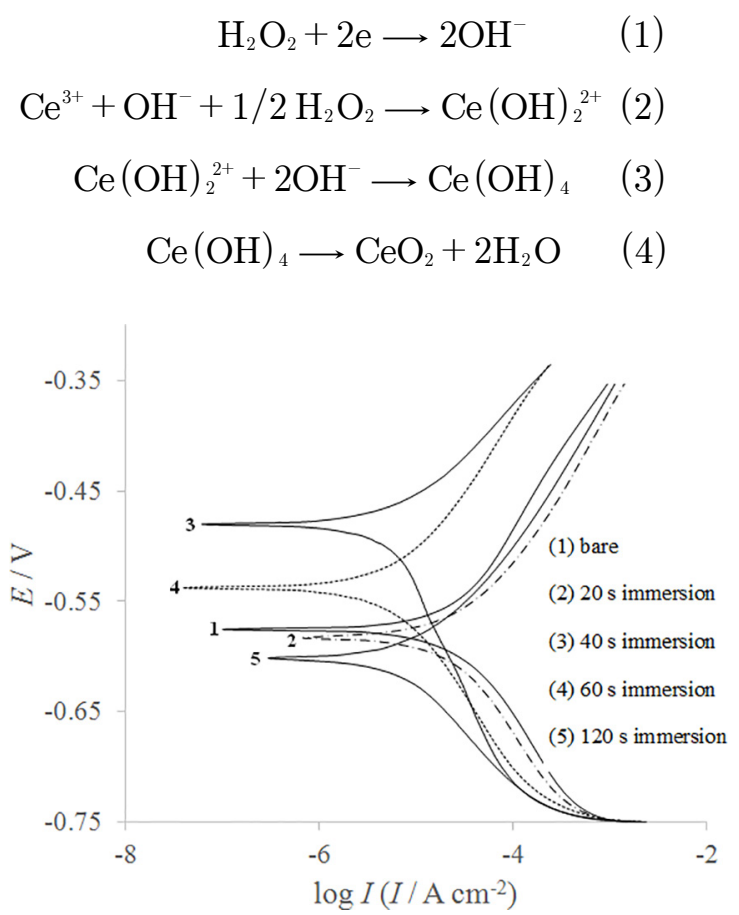

Figure 1. Potentiodynamic polarization curves of cerium-coated steel in $3.5 \mathrm{wt} \% \mathrm{NaCl}$ solution. Conversion coatings were obtained at $25^{\circ} \mathrm{C}$ in cerium solution with different immersion times: (1) bare, (2) $20 \mathrm{~s}$, (3) $40 \mathrm{~s}$, (4) $60 \mathrm{~s}$ and (5) $120 \mathrm{~s}$.

$\mathrm{H}_{2} \mathrm{O}_{2}$ is added to the coating bath as an effective accelerator additive. The acceleration provide by the $\mathrm{H}_{2} \mathrm{O}_{2}$ may be due to the rapid increase in $\mathrm{pH}$ caused by $\mathrm{H}_{2} \mathrm{O}_{2}$ reduction in cathodic sites which would improve the deposition of cerium oxide and cerium Hydroxide ${ }^{42}$. Hughes et al. ${ }^{43}$ reported that during the cerium conversion coatings process, the ceria particle size was increased with the immersion time. They 
Table 1. Potentiodynamic polarization parameters of different immersion times for the cerium coatings in $3.5 \mathrm{wt}$ \% $\mathrm{NaCl}$ solution. Coatings were prepared by immersion in cerium solution in $25^{\circ} \mathrm{C}$.

\begin{tabular}{ccccccc}
\hline Immersion time & $E_{\text {corr }} / \mathrm{V}$ & $I_{\text {corr }} / \mathrm{A} \mathrm{cm}^{-2}$ & $\beta_{\mathrm{a}} / \mathrm{V}$ & $-\beta_{\mathrm{c}} / \mathrm{V}$ & $R_{p} / \mathrm{ohm}$ & $\mathrm{CR}$ \\
\hline 0 (Bare) & -0.575 & $4.807 \times 10^{-6}$ & 0.041 & 0.049 & $2.016 \times 10^{+3}$ & $5.646 \times 10^{-2}$ \\
$20 \mathrm{~s}$ & -0.583 & $3.341 \times 10^{-6}$ & 0.029 & 0.033 & $2.006 \times 10^{+3}$ & $3.925 \times 10^{-2}$ \\
$40 \mathrm{~s}$ & -0.48 & $1.246 \times 10^{-6}$ & 0.05 & 0.038 & $7.524 \times 10^{+3}$ & $1.464 \times 10^{-2}$ \\
$60 \mathrm{~s}$ & -0.538 & $9.471 \times 10^{-7}$ & 0.032 & 0.041 & $8.239 \times 10^{+3}$ & $1.112 \times 10^{-2}$ \\
$120 \mathrm{~s}$ & -0.602 & $1.112 \times 10^{-6}$ & 0.028 & 0.021 & $4.685 \times 10^{+3}$ & $1.306 \times 10^{-2}$ \\
\hline
\end{tabular}

suggested that the increase in the particle size was probably related to an increase in the $\mathrm{pH}$ near the surface because the rate of the hydrolysis of cerium ions is increased at a higher $\mathrm{pH}$. The particle size in conversion coatings is related to nucleation rate. With increasing nucleation rate, more preliminary nucleus of cerium oxide is created on surface and thus the overall size of cerium oxide particles decreases. Higher $\mathrm{pH}$ of cathodic sites increases the nucleation rate of cerium oxide particles and preliminary nucleus can be formed on all cathodic sites. Thus, with increasing $\mathrm{pH}$ in all cathodic sites, more nucleuses are created. These preliminary nucleuses grow with increasing immersion time. Growth of many nucleuses with increasing immersion time leads to more uniform cerium conversion coating. If the number of preliminary nucleus decreases due to low nucleation rate, external growth of deposits is obtained with increasing immersion time and uniformity of coating reduces and leads to more cracking of coatings.

As can be seen, by increasing immersion time from 20 to $60 \mathrm{~s}, I_{\text {corr }}$ and corrosion rate of the coated samples decreases. But after $60 \mathrm{~s}$ corrosion current density and corrosion rate increases. Increasing immersion time causes the propagation of cerium oxide on the surface, however still some parts of the sample remain bare. In addition, cerium oxide coatings in very low immersion times are thin. Cerium oxide covers the entire sample by increasing immersion time to $60 \mathrm{~s}$. By increasing the immersion time, the cerium oxide layer has enough time to settle on the steel surface, and produce a proper thickness for corrosion protection. In very high immersion time, about $120 \mathrm{~s}$, the corrosion rate cerium oxide coated steel increases. In all immersion time, cerium conversion coatings indicate cracked features and in very high immersion time, the size of cracks increases. Propagation of cracks on the film relates to the growth of the film's thickness which leads to decreasing coating toughness. By withdrawing samples from the solution and drying them at ambient temperature, cracks progress on their surface and decrease the corrosion resistance of the coatings. The upper layer of the coating hardens during drying process and water is trapped in inner cerium oxide layer. So the trapped water cannot release from the coating because of the presence of the top hard layer and lead to porosity and cracking. The loos area of coating can be used as the site of cathodic reaction and thus the area of cathodic reaction increases in very high immersion time which leads to increasing corrosion rate.
The nyquist diagrams of cerium oxide coated steel X52 obtained after different immersion times in the cerium bath are presented in Figure 2. Electrochemical impedance was employed to confirm the anticorrosion behavior of the cerium oxide coatings. A depressed capacitive loop in nyquist diagrams is obtained which is due to the charge transfer resistance and double layer capacitance. The equivalent circuit compatible with the Nyquist diagram is depicted in Figure 3. In this electrical equivalent circuit, $R, Q_{\mathrm{d}}$, and $R_{\mathrm{ct}}$ represent solution resistance, a constant phase element corresponding to the double layer capacitance $Q_{d l}=R^{n-1} C_{d l}^{n}$, and the charge transfer resistance. To obtain a satisfactory impedance simulation of cerium oxide coated aluminum, it is necessary to replace the capacitor $(C)$ with a constant phase element (CPE) $Q$ in the equivalent circuit. The most widely accepted explanation for the presence of CPE behavior and depressed semicircles on solid electrodes is microscopic roughness, causing an inhomogeneous distribution in the solution resistance as well as in the double layer capacitance ${ }^{44,45}$.

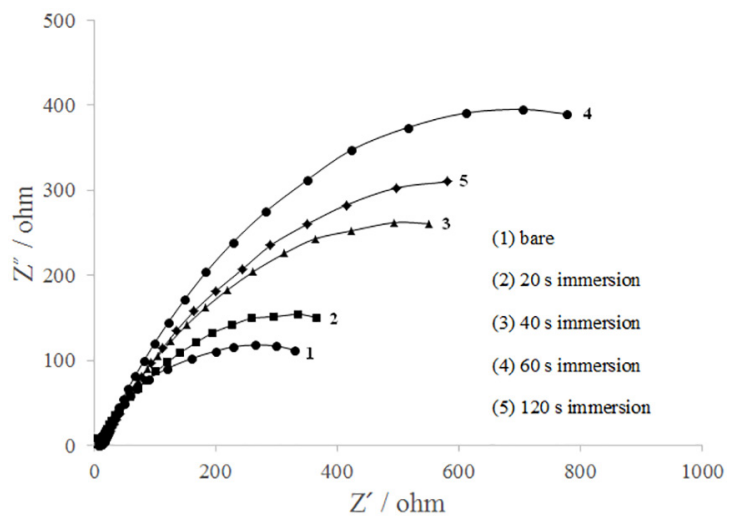

Figure 2. The Nyquist plots of cerium-coated steel in $3.5 \mathrm{wt} \% \mathrm{NaCl}$ solution. Conversion coatings were obtained in cerium solution with different immersion times: (1) bare, (2) $20 \mathrm{~s}$, (3) $40 \mathrm{~s}$, (4) 60 $\mathrm{s}$ and (5) $120 \mathrm{~s}$.

To corroborate the equivalent circuit, the experimental data are fitted to the equivalent circuit and the circuit elements are obtained. Table 2 illustrates the equivalent circuit parameters for the impedance spectra of corrosion of cerium oxide coated steel in $\mathrm{NaCl}$ solution. From Table 2 it is seen that, with increasing immersion time in the coating solution, the charge transfer resistance increases which is due to the 


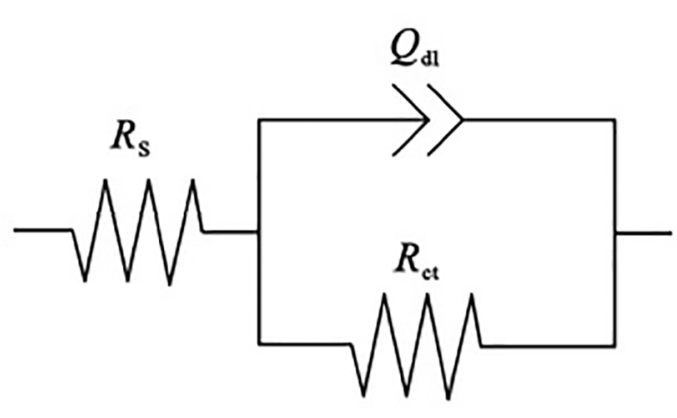

Figure 3. Equivalent circuits compatible with the experimental impedance data in Figure 2 for corrosion of cerium oxide coated steel electrode.

presence of the more adherent and uniform cerium coating on the surface of steel X52, which will decrease the active area of the substrate. This is followed by a slow decrease of the impedance after $60 \mathrm{~s}$ immersion in the cerium bath due to larger cracks. This is in agreement with the potentiodynamic polarization data.

\subsection{Effect of immersion temperature}

The polarization curves of steel electrode with cerium oxide coatings in $3.5 \% \mathrm{NaCl}$ solution are given in Figure 4. Coatings were obtained by $60 \mathrm{~s}$ immersion time in the cerium bath at different temperature and the corresponding corrosion parameters are presented in Table 3 . It can be seen that by increasing temperature from 25 to $65^{\circ} \mathrm{C}, I_{\text {corr }}$ and corrosion rate of the coated samples increase. The cerium oxide conversion coatings prepared at $25^{\circ} \mathrm{C}$ shows the highest polarization resistance and the lowest corrosion current density due to the compact structure of coating.

Nyquist plots at $\mathrm{OCP}$ for the cerium conversion coating obtained by $60 \mathrm{~s}$ immersion time in the cerium bath at different temperature are presented in Figure 5. All coatings indicate

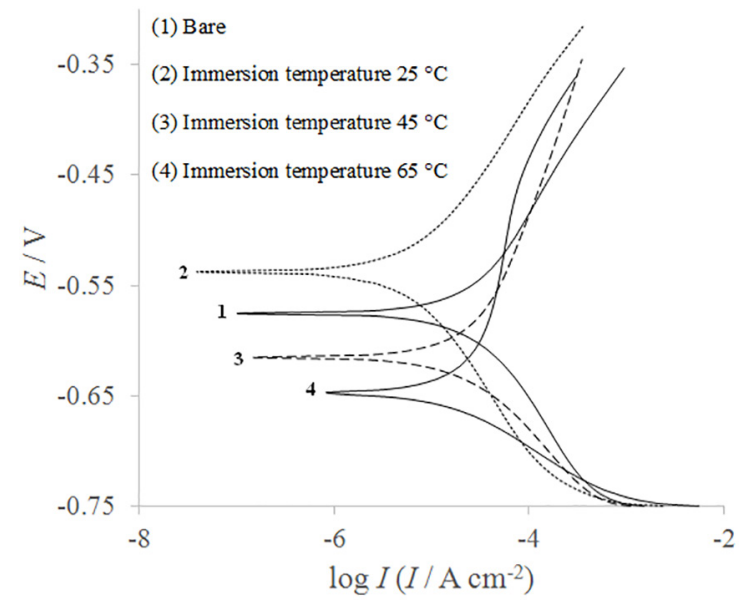

Figure 4. Potentiodynamic polarization curves of cerium-coated steel in $3.5 \mathrm{wt} \% \mathrm{NaCl}$ solution. Conversion coatings were obtained by $60 \mathrm{~s}$ immersion time in cerium solution in different temperatures: (1) bare, (2) $25^{\circ} \mathrm{C}$, (3) $45^{\circ} \mathrm{C}$ and (4) $65^{\circ} \mathrm{C}$.

capacitive loop attributed to the double layer capacitance and the charge transfer resistance. The experimental data were fitted to the equivalent circuit by using constant phase element (Figure 3). The obtained impedance data were illustrated in Table 4 for cerium coated steel in different operating temperature. According to Table 4, with increasing operating temperature, the corrosion resistance decreases. This is due to the increase in dissolution rate of steel in higher temperature in cerium bath. High corrosion rate in higher temperature decreases the active sites on steel surface for cerium oxide deposition.

\subsection{Surface analysis}

The cerium conversion coatings of aluminum obtained after different immersion times in cerium solution are presented in Figure 6. The cerium conversion coatings show cracked morphology in all immersion times. These features were

Table 2. Impedance parameters of different immersion times for the coatings cerium in $3.5 \mathrm{wt} . \% \mathrm{NaCl}$ solution. Coatings were prepared by immersion in cerium solution in $25^{\circ} \mathrm{C}$.

\begin{tabular}{ccccc}
\hline Immersion time & $R_{s} / \Omega$ & $R_{c t} / \Omega$ & $Q_{d l} / \mathrm{F}$ & 0.6 \\
\hline 0 (Bare) & 5.5 & 483 & 0.013 & 0.012 \\
$20 \mathrm{~s}$ & 5.9 & 597 & 0.01 & 0.62 \\
$40 \mathrm{~s}$ & 6.2 & 954 & 0.008 & 0.61 \\
$60 \mathrm{~s}$ & 6.1 & 1415 & 0.011 & 0.63 \\
$120 \mathrm{~s}$ & 5.8 & 1139 & & \\
\hline
\end{tabular}

Table 3. Potentiodynamic polarization parameters of different operating temperature for the cerium coatings in $3.5 \mathrm{wt}$. $\% \mathrm{NaCl}$ solution. Coatings were prepared by $60 \mathrm{~s}$ immersion time in cerium solution.

\begin{tabular}{ccccccc}
\hline Temperature & $E_{\text {corr }} / \mathrm{V}$ & $I_{\text {corr }} / \mathrm{A} \mathrm{cm}^{-2}$ & $\beta_{a} / \mathrm{V}$ & $-\beta_{c} / \mathrm{V}$ & $R_{\mathrm{p}} / \mathrm{ohm}$ & $\mathrm{CR}$ \\
\hline Bare & -0.575 & $4.807 \times 10^{-6}$ & 0.041 & 0.049 & $2.016 \times 10^{+3}$ & $5.646 \times 10^{-2}$ \\
$25^{\circ} \mathrm{C}$ & -0.538 & $9.471 \times 10^{-7}$ & 0.032 & 0.041 & $8.239 \times 10^{+3}$ & $1.112 \times 10^{-2}$ \\
$45^{\circ} \mathrm{C}$ & -0.615 & $2.44 \times 10^{-6}$ & 0.023 & 0.026 & $2.172 \times 10^{+3}$ & $2.867 \times 10^{-2}$ \\
$65^{\circ} \mathrm{C}$ & -0.648 & $2.448 \times 10^{-6}$ & 0.02 & 0.029 & $2.099 \times 10^{+3}$ & $2.875 \times 10^{-2}$ \\
\hline
\end{tabular}


Table 4. Impedance parameters of different operating temperature for the cerium coatings in $3.5 \mathrm{wt} \% \mathrm{NaCl}$ solution. Coatings were prepared by $60 \mathrm{~s}$ immersion time in cerium solution.

\begin{tabular}{ccccc}
\hline Temperature & $R_{s} / \Omega$ & $R_{c t} / \Omega$ & $Q_{d l} / \mathrm{F}$ & 0.6 \\
\hline Bare & 5.5 & 483 & 0.013 & 0.64 \\
$25^{\circ} \mathrm{C}$ & 6.1 & 1415 & 0.008 & 0.63 \\
$45^{\circ} \mathrm{C}$ & 5.5 & 782 & 0.012 & 0.62 \\
$65^{\circ} \mathrm{C}$ & 5.3 & 862 & 0.013 & 0.62 \\
\hline
\end{tabular}

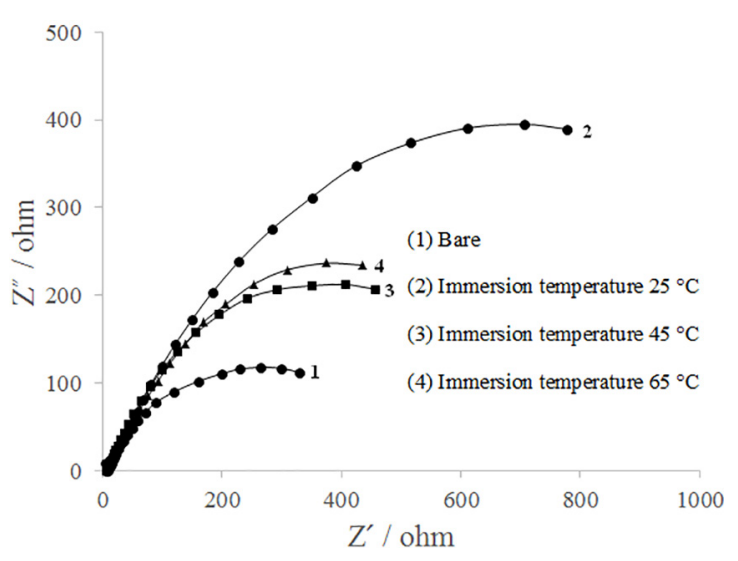

Figure 5. The Nyquist plots of cerium-coated steel in $3.5 \mathrm{wt} \% \mathrm{NaCl}$ solution. Conversion coatings were obtained by $60 \mathrm{~s}$ immersion time in cerium solution in different temperatures: (1) bare, (2) $25^{\circ} \mathrm{C}$, (3) $45^{\circ} \mathrm{C}$ and (4) $65^{\circ} \mathrm{C}$.

attributed to the drying process performed after the samples have been taken out of the conversion bath. Figure 4a shows SEM micrograph of the cerium oxide coated steel obtained with $20 \mathrm{~s}$ immersion time. It can be seen that, the coating is thin and does not cover the whole surface because there would not be enough time to form a continuous layer above surface. The micrograph of the coating obtained higher immersion times indicates thicker cerium oxide coatings. The coating prepared by $60 \mathrm{~s}$ immersion in cerium bath (Figure 6c) shows a more uniform surface. After $60 \mathrm{~s}$, a very thick film forms on the surface and causes to increase the stress in the coating structure. This internal stress leads to increasing initiation and propagation of more cracks on the surface (Figure 6d). Larger cracks cause higher corrosion rate which confirms the result of polarization.

The corresponding EDX analysis is shown in Figure 7. Based on the EDS results, the cerium oxide conversion coating is mainly composed of $\mathrm{Fe}, \mathrm{Ce}$ and $\mathrm{O}$. Cerium content increases by increasing immersion time (Table 5). The significant decrease in the concentration of $\mathrm{Fe}$ on the

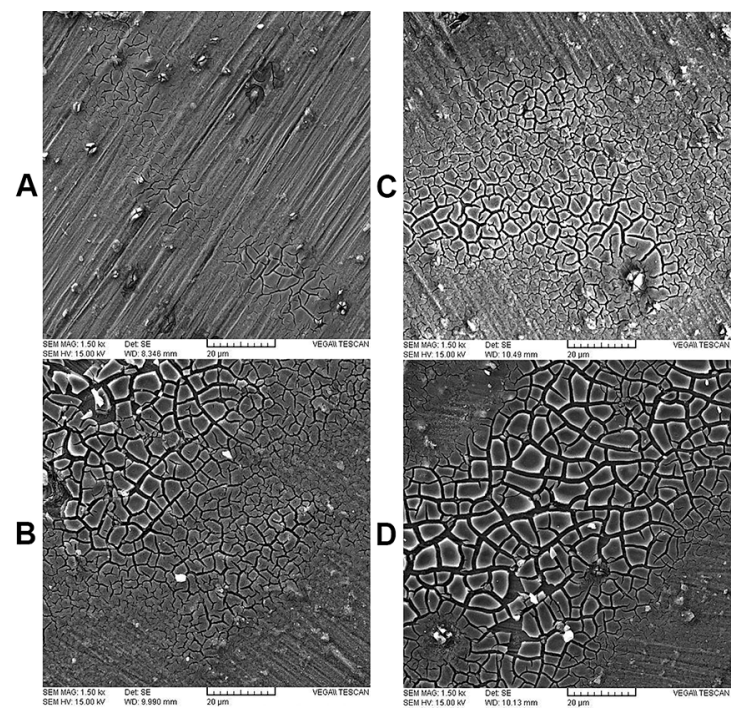

Figure 6. SEM micrographs of steel samples coated at different immersion times in cerium chloride solution: (a) $20 \mathrm{~s}$, (b) $40 \mathrm{~s}$, (c) $60 \mathrm{~s}$, and (d) $120 \mathrm{~s}$.

Ce treated sample may confirm that thicker and denser layer with higher surface coverage is formed.

\section{Conclusions}

Cerium oxide conversion coatings were prepared on steel X 52 by dip immersion method. The effect of immersion times and immersion temperatures were investigated on microstructural features and electrochemical corrosion behavior of steel in $3.5 \% \mathrm{wt} \mathrm{NaCl}$ solution. The cerium-based conversion coating improved the corrosion resistance of the alloy due to inhibition of the anodic and cathodic reaction in chloride-containing environment. Immersion time in the cerium solution had an important influence on the corrosion properties and more uniform coating with higher corrosion resistance was obtained by $60 \mathrm{~s}$ immersion. The coating

Table 5. EDX analysis of cerium conversion coatings obtained after different immersion times.

\begin{tabular}{cccc}
\hline Immersion time & Weight $\%$ of $\mathrm{Fe}$ & Weight $\%$ of Ce & Weight $\%$ of O \\
\hline $20 \mathrm{~s}$ & 89.66 & 2.05 & 8.29 \\
$40 \mathrm{~s}$ & 77.70 & 5.81 & 16.49 \\
$60 \mathrm{~s}$ & 75.71 & 6.70 & 17.59 \\
$120 \mathrm{~s}$ & 68.44 & 12.46 & 19.10 \\
\hline
\end{tabular}



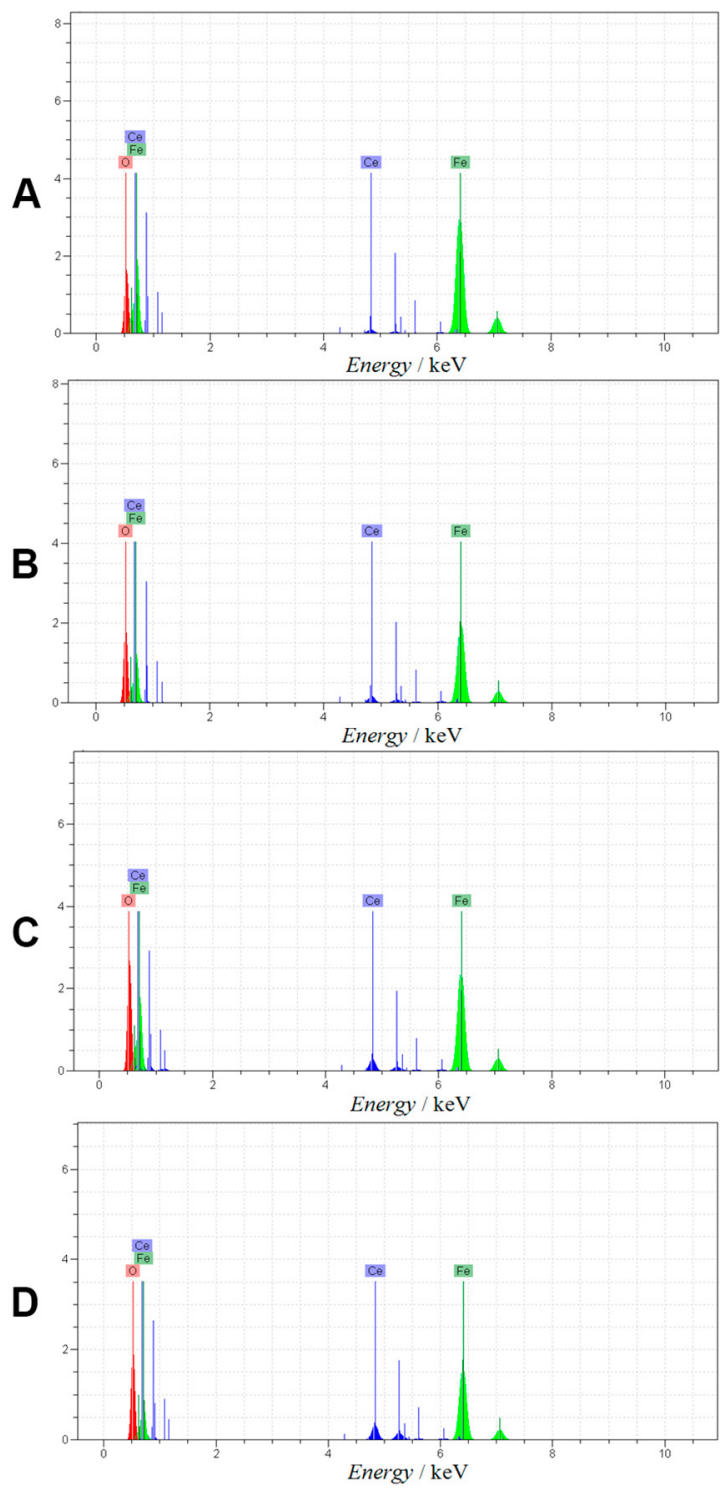

Figure 7. EDX analysis of steel samples coated at different immersion times in cerium chloride solution: (a) $20 \mathrm{~s}$, (b) $40 \mathrm{~s}$, (c) $60 \mathrm{~s}$, and (d) $120 \mathrm{~s}$.

produced for shorter immersion time was thin and not uniform, while the longer immersion time led to a highly cracked coating. In addition, electrochemical data indicated that the corrosion resistance decreased with increasing the operating temperature.

\section{References}

1. Ballesteros AF, Gomes JAP, Bott IS. Corrosion Evaluation of SAW Welded API 5L X-80 Joints in H2S-Containing Solution. Materials Research. 2015;18(2):417-426.

2. Ferreira LRM, Ponte HA, Sanches LS, Abrantes ACTG. $\mathrm{CO}_{2}$ Corrosion in the Region Between the Static and Turbulent Flow Regimes. Materials Research. 2015;18(2):245-249.
3. Pereira RFC, Oliveira ESD, Lima MAGA, Brasil SLDC. Corrosion of Galvanized Steel Under Different Soil Moisture Contents. Materials Research. 2015;18(3):563-568.

4. Karimi A, Danaee I, Eskandari H, RashvanAvei M. Electrochemical investigations on the inhibition behavior and adsorption isotherm of synthesized di-(Resacetophenone)-1,2-cyclohexandiimine Schiff base on the corrosion of steel in $1 \mathrm{M} \mathrm{HCl}$. Protection of Metals and Physical Chemistry of Surfaces. 2015;51(5):899-907.

5. Rocha JC, Gomes JACP, D'Elia E. Aqueous extracts of mango and orange peel as green inhibitors for carbon steel in hydrochloric acid solution. Materials Research. 2014;17(6):1581-1587.

6. Uygur I, Gerengi H, Arslan Y, Kurtay M. The Effects of Cryogenic Treatment on the Corrosion of AISI D3 Steel. Materials Research. 2015;18(3):569-574.

7. Santana PMB, Meira M, Tentardini EK. Effects of Adding Some Natural Substances to Biodiesel to Control its Effect on Carbon Steel Corrosion. Materials Research. 2015;18(Supl 2):164-169.

8. Barros IB, Kappel MAA, Santos PM, Veiga Junior VF, D’Elia E, Bastos IN. The inhibitory action of Bauhinia purpurea extracts on the corrosion of carbon steel in sulfuric acid medium. Materials Research. 2016;19(1):187-194.

9. RameshKumar S, Danaee I, RashvandAvei M, Vijayan M. Quantum chemical and experimental investigations on equipotent effects of $(+) \mathrm{R}$ and $(-) \mathrm{S}$ enantiomers of racemic amisulpride as eco-friendly corrosion inhibitors for mild steel in acidic solution. Journal of Molecular Liquids. 2015;212:168-186.

10. Longhi M, Kunsta SR, Beltrami LVR, Kerstner EK, Silva Filho CI, Sarmento VHV, et al. Effect of Tetraethoxy-silane (TEOS) Amounts on the Corrosion Prevention Properties of Siloxane-PMMA Hybrid Coatings on Galvanized Steel Substrates. Materials Research. 2015;18(6):1140-1155.

11. Tomachuk CR, Elsner CI, Di Sarli AR. Electrochemical characterization of chromate free conversion coatings on electrogalvanized steel. Materials Research. 2014;17(1):61-68.

12. Kazemi M, Danaee I, Zaarei D. Deposition and corrosion behavior of silicate conversion coatings on aluminum alloy 2024. Materialwissenschaft und Werkstofftechnik. 2014;45(7):574-581.

13. Khan SA, Miyashita Y, Mutoh Y. Corrosion fatigue behavior of AM60 magnesium alloy with anodizing layer and chemical-conversion-coating layer. Materials and Corrosion. 2015;66(9):940-948.

14. Sun RX, Wang PF, Zhao DD, Sun ZZ, Li CQ, Chen KZ. An environment-friendly calcium phosphate conversion coating on AZ91D alloy and its corrosion resistance. Materials and Corrosion. 2015;66(4):383-386.

15. Kazemi M, Danaee I, Zaarei D. The effect of pre-anodizing on corrosion behavior of silicate conversion coating on AA2024. Materials Chemistry and Physics. 2014;148(1-2):223-229.

16. Campestrini P, Böhm S, Schram T, Terryn H, de Wit JHW. Study of the formation of chromate conversion coatings on Alclad 2024 aluminum alloy using spectroscopic ellipsometry. Thin Solid Films. 2002;410(1-2):76-85. 
17. Kanani M, Danaee I, Maddahy MH. Microstructural characteristics and corrosion behavior of cerium oxide conversion coatings on AA6063. Materials and Corrosion. 2014;65(11):1073-1079.

18. Danaee I, Zamanizadeh HR, Fallahi M, Lotfi B. The effect of surface pre-treatments on corrosion behavior of cerium-based conversion coatings on Al 7075-T6. Materials and Corrosion. 2014;65(8):815-819.

19. Salazar-Banda GR, Moraes SR, Motheo AJ, Machado SAS. Anticorrosive cerium-based coatings prepared by the solgel method. Journal of Sol-Gel Science and Technology. 2009;52(3):415-423.

20. Bahri H, Danaee I, Rashed GR. The effect of curing time and curing temperature on the corrosion behavior of nanosilica modified potassium silicate coatings on AA2024. Surface and Coatings Technology. 2014;254:305-312.

21. Johnson BY, Edington J, O'Keefe MJ. Effect of coating parameters on the microstructure of cerium oxide conversion coatings. Materials Science and Engineering: A. 2003;361(1-2):225-231.

22. Asadi V, Danaee I, Eskandari H. The Effect of Immersion Time and Immersion Temperature on the Corrosion Behavior of Zinc Phosphate Conversion Coatings on Carbon Steel. Materials Research. 2015;18(4):706-713.

23. Johansen HD, Brett CMA, Motheo AJ. Corrosion protection of aluminium alloy by cerium conversion and conducting polymer duplex coatings. Corrosion Science. 2012;63:342-350.

24. Paussa L, Andreatta F, Rosero Navarro NC, Durán A, Fedrizzi L. Study of the effect of cerium nitrate on AA2024-T3 by means of electrochemical micro-cell technique. Electrochimica Acta. 2012;70:25-33.

25. Song D, Feng X, Sun M, Ma X, Tang G. Composition and corrosion resistance of cerium conversion films on 2195Al-Li alloy. Journal of Rare Earths. 2012;30(4):383-387.

26. Sánchez-Amaya JM, Blanco G, Garcia-Garcia FJ, Bethencourt M, Botana FJ. XPS and AES analyses of cerium conversion coatings generated on AA5083 by thermal activation. Surface and Coatings Technology. 2010;213:105-116.

27. Olivier M, Lanzutti A, Motte C, Fedrizzi L. Influence of oxidizing ability of the medium on the growth of lanthanide layers on galvanized steel. Corrosion Science. 2010;52(4):1428-1439.

28. Machkova M, Matter EA, Kozhukharov S, Kozhukharov V. Effect of the anionic part of various Ce(III) salts on the corrosion inhibition efficiency of AA2024 aluminium alloy. Corrosion Science. 2013;69:396-405.

29. Hu J, Zhao XH, Tang SW, Sun MR. Corrosion protection of aluminum borate whisker reinforced AA6061 composite by cerium oxide-based conversion coating. Surface and Coatings Technology. 2006;201(6):3814-3818.

30. Bahri H, Danaee I, Rashed GR, Zaarei D. Effect of Silica Ratio on the Corrosion Behavior of Nano-silica Potassium Silicate Coatings on Aluminum Alloy 2024. Journal of Materials Engineering and Performance. 2015;24(2):839-847.

31. Rivera BE, Johnson BY, O'Keefe MJ, Fahrenholtz WG. Deposition and characterization of cerium oxide conversion coatings on aluminum alloy 7075-T6. Surface and Coatings Technology. 2004;176(3):349-356.
32. Wang C, Jiang F, Wang F. Cerium Chemical Conversion Coating for Aluminum Alloy 2024-T3 and Its Corrosion Resistance. Corrosion. 2004;60(3):237-243.

33. Brunelli K, Dabalà M, Calliari I, Magrini M. Effect of $\mathrm{HCl}$ pretreatment on corrosion resistance of cerium-based conversion coatings on magnesium and magnesium alloys. Corrosion Science. 2005;47(4):989-1000.

34. Danaee I, Kanaani M, Maddahy MH, Nikmanesh S. Corrosion behavior of Ce-oxide/hydroxide coated AA7075-T6 prepared by dip immersion method. Turkish Journal of Engineering \& Environmental Sciences. 2014;38(3):363-372.

35. Jamali F, Danaee I, Zaarei D. Effect of nano-silica on the corrosion behavior of silicate conversion coatings on hot-dip galvanized steel. Materials and Corrosion. 2015;66(5):459-464.

36. Onofre-Bustamante E, Domínguez-Crespo MA, Torres-Huerta AM, Olvera Martínez A, Genescá-Llongueras J, Rodríguez-Gómez FJ. Characterization of cerium-based conversion coatings for corrosion protection of AISI-1010 commercial carbon steel. Journal of Solid State Electrochemistry. 2009;13(11):1785-1799.

37. Danaee I, Noori S. Kinetics of the hydrogen evolution reaction on NiMn graphite modified electrode. International Journal of Hydrogen Energy. 2011;36(19):12102-12111.

38. Macdonald JR. Note on the parameterization of the constant-phase admittance element. Solid State Ionics. 1984;13(2):147-149.

39. Danaee I, Bahramipanah N. Thermodynamic and adsorption behavior of $\mathrm{N}_{2} \mathrm{O}_{4}$ schiff base as a corrosion inhibitor for API-5L-X65 steel in $\mathrm{HCl}$ solution. Russian Journal of Applied Chemistry. 2016;89(3):489-499.

40. Conde A, Arenas M, de Frutos A, de Damborenea J. Effective corrosion protection of 8090 alloy by cerium conversion coatings. Electrochimica Acta. 2008;53(26):7760-7768.

41. Aballe A, Bethencourt M, Botana FJ, Cano MJ, Marcos M. Inhibition of the corrosion process of alloy AA5083 (Al-Mg) in seawater by cerium cations. An EIS study. Materials and Corrosion. 2001;52(5):344-350.

42. Campestrini P, Terryn H, Hovestad A, de Wit JHW. Formation of a cerium-based conversion coating on AA2024: relationship with the microstructure. Surface and Coatings Technology. 2004;176(3):365-381.

43. Hughes AE, Gorman JD, Miller PR, Sexton BA, Paterson PJK, Taylor RJ. Development of cerium-based conversion coatings on 2024-T3 Al alloy after rare-earth desmutting. Surface and Interface Analysis. 2004;36(4):290-303.

44. Danaee I, Gholami M, RashvandAvei M, Maddahy MH. Quantum chemical and experimental investigations on inhibitory behavior of amino-imino tautomeric equilibrium of 2-aminobenzothiazole on steel corrosion in $\mathrm{H}_{2} \mathrm{SO}_{4}$ solution. Journal of Industrial and Engineering Chemistry. 2015;26:81-94.

45. Jafari H, Danaee I, Eskandari H, RashvandAvei M. Combined Computational and Experimental Study on the Adsorption and Inhibition Effects of $\mathrm{N}_{2} \mathrm{O}_{2}$ Schiff Base on the Corrosion of API 5L Grade B Steel in $1 \mathrm{~mol} / \mathrm{L} \mathrm{HCl}$. Journal of Materials Science \& Technology. 2014;30(3):239-252. 